\title{
Pragmatic Transfer in the Speech Act of Compliment among Chinese EFL Learners
}

\author{
Yue Lin* \\ School of Foreign Languages \& Literature, Yunnan Normal University, Kunming 650500, China \\ *Corresponding author: Yue Lin, kittyylin@ hotmail.com
}

\begin{abstract}
This article reviews the notions of transfer and its subcategories of positive transfer as well as negative transfer. This article also considers the research on pragmatic transfer in the speech act of compliment in first language as well as second and foreign language contexts. In addition, it further explores three research questions concerning pragmatic transfer in compliment among Chinese EFL (English as a foreign language) learners.
\end{abstract}

Keywords: Pragmatic transfer; Speech act; Compliment

Publication date: August 2021; Online publication: August 30, 2021

\section{Introduction}

With the advent and quickening pace of globalization, the necessity and significance of successful crosscultural and intercultural communications have become more and more apparent in the global environment ${ }^{[1]}$, especially in bilingual educational situations. However, different cultures contain different perceptions and interpretations of appropriateness and politeness. As Lado had pointed out ${ }^{[2]}$, "If we ignore these cultural differences, we will misjudge our cultural neighbor, as we constantly do at present, for a form of behavior that to them has one meaning may have another to us. If we do not know of the difference in meaning, we would ascribe our neighbors the intentions that the same behavior would imply for us and pass them the same judgment as our confreres."

Consequently, cross-cultural communication posits inherent risks of communication failure [3]. Therefore, the cultivation and acquisition of efficient as well as effective cross-cultural communicative competence by second and foreign language learners in bilingual educational situations have aroused the attention and interests from many researchers. In consideration of second and foreign language learners, linguistic knowledge alone does not mean a learner can be successful in actual communication, and the inappropriate use of a language may cause misunderstandings; a learner's pragmatic competence is therefore vital in most bilingual educational situations ${ }^{[1]}$. As far as the Chinese EFL is concerned, the main purpose of English language learning and teaching in China is to enable the learners to cultivate and acquire appropriate pragmatic and communicative competence, which means that during the process of crosscultural communication, one should be equipped with the ability to select a linguistic form that is appropriate for a specific situation, or to use English appropriately in social interactions (Hymes, 1981).

A great number of researchers have studied the different aspects of speech acts; for instance, requests (Scarcella, 1979; Olshtain \& Blum-Kulka, 1985; Blum-Kulka \& House, 1989; Svanes, 1992; S. Takahashi, 1996), apologies (Olshtain \& Blum-Kulka, 1985; Trosborg, 1975; Maeshiba, et al., 1996), complaints (Olshtain \& Weinbach, 1978), and gratitude (Bodman \& Eisenstein, 1988). Additionally, compliment, as a speech act, received relatively less attention, but it is the most common speech act existing in different cultures, which is a good domain for the exploration of pragmatic transfer ${ }^{[1]}$. In this article, a study of 
compliment is presented to report the Chinese students' pragmatic failures and pragmatic transfer from their "mother tongue references" (Yan \& He, 1990: 185).

\section{Literature review}

\subsection{Definitions of language transfer}

Over decades, the role of transfer in ESL and EFL bilingual educational situations has been studied by many researchers, they assert that the transfer phenomenon lies embedded in the foreign language and second language learning or acquisition process. Transfer, which plays an important role in shaping interlanguage (e.g. Gass \& Selinker, 1983), would influence the learning and acquisition of second language as well as foreign language; it is indeed one of the main factors that affect the success of second language learning ${ }^{[1]}$ and foreign language learning. In consequence, language transfer is indispensable in bilingual contexts, in which it contains broad scope and wide connotations.

\subsection{Pragmatics and pragmatic transfer}

Pragmatics is the study of the use of context influences meaning (He, 2003:2). The term "pragmatics" was first introduced in Foundations of the Theory of Signs by Charles W. Morris in 1938. For Morris, pragmatics is the study of the relations of signs to interpreters. In order to make it more comprehensible, He's (2003) definition regarding pragmatics lies in two aspects: 1) Pragmatics is the study of language comprehension and application; 2) Pragmatics is the study of language appropriateness and tactfulness, in which it deals with the way of how to use language tactfully and understand appropriately (2003: 2-6).

Beebe, Takahashi, and Uliss-Weltz view pragmatic transfer as the transfer of L1 socio-cultural competence in performing L2 speech acts or any other aspects of L2 conversation, where the speaker is trying to achieve a particular function of language ${ }^{[4]}$. Kasper also asserts that pragmatic transfer in interlanguage pragmatics refers to the influences exerted by the learners' pragmatic knowledge of languages and cultures other than L2 on their comprehensive production and learning of L2 pragmatic information ${ }^{[5]}$. Therefore, transfer can also be the transfer of language knowledge, cultures, and pragmatic competence.

\subsection{Speech act of compliment}

\subsubsection{Social functions of compliment}

Compliments are positive expression or evaluation, which are directed either explicitly or implicitly to someone for something valued positively by the speaker and the hearer, as well as the whole speech community ${ }^{[6,7]}$. It seems that the major function of compliments is to establish and maintain social rapport (Manes and Wolfson, 1981: 124) as well as the smoothness between participants (Chen, 2002: 1). Since the speech act of complimenting can be complicated and confusing, it is vitally important to identify them and generate appropriate responses to avoid pragmalinguistic and sociopragmatic failure ${ }^{[8]}$.

\subsubsection{Compliment formulas}

Manes and Wolfson (1981: 123) found that the speech act of complimenting is characterized by the formulaic nature of its syntactic and semantic composition. Then, they claimed that the following three most commonly occurring syntactic patterns can account for $85 \%$ of the compliments in American English:

(1) NP is/looks (intensifier) ADJ.

Your hair looks really good. 
(2) I (intensifier) like/love NP.

I really like these shoes.

(3) PRON is (intensifier) (a) ADJ NP.

That's really a beautiful car. (Formula cited in Du, 1999:138-139)

Note: NP (noun phrase); ADJ (adjective); PRON (pronoun)

Generally speaking, Ye's data of Chinese compliments were quite similar to these formulas in American English. However, she also pointed out that the positive semantic carrier in a Chinese compliment can be realized by either an adjective/stative verb, an adverb, a noun, or a verb ${ }^{[7]}$.

\section{Research}

\subsection{Aim}

As discussed in the previous parts, this study is conducted to discover:

(1) Is there pragmatic transfer among Chinese EFL learners when they offer compliments in English?

(2) How do Chinese EFL learners transfer the speech act of compliment during their English learning process?

(3) Is there any relationship between English proficiency and pragmatic transfer? Is there more transfer among learners of intermediate- or high-level English proficiency?

\subsection{Data collection method}

\subsubsection{Participants}

Two groups of learners, who have spent different durations in learning English (regarded as different levels of English proficiency), were asked to complete the discourse completion task (DCT). The first group comprised of 20 participants from an English department of a college in Kunming. They are first-year English majors; meaning that they have studied English for seven years. All of them scored relatively high in the English test for the National College Entrance Examination. The English language requirement for their admission to the university is comparatively high. They are referred as the advanced English proficiency group (AEPG).

The second group comprised of 20 freshmen, who are majoring in computer and science, from another university in Kunming. They have learned English for five years, and according to their English test scores (which ranged from 70 to 90 points out of 150 points) in the National College Entrance Examination, they are defined as the intermediate English proficiency group (IEPG).

\subsubsection{Materials and procedure}

Information and data were collected by means of the written form of the discourse completion task (DCT) in English.

The DCT comprised of five compliment situational statements, so in total, there were five statements with five points. The participants were required to write down their possible replies to the five situations. In order to avoid potential misunderstandings, the instructions for the completion of the DCT were explained in Mandarin. The duration to complete the DCT was set as 30 minutes. Forty valid completed DCTs were collected, and each of the completed DCT was assessed by two English native speakers who were selected from the same cultural background. 


\subsection{Data analysis}

Table 1 and Table 2 display the total number of wrong replies (which are related to pragmatic transfer) and correct replies (no pragmatic transfer) for the five situational statements of each participant in IEPG and AEPG, respectively. The total number of wrong replies for each statement was also counted along with the percentages.

In Table 1, it can be seen that not a single participant in the intermediate group (IEPG) had all 5 replies correct. This indicates that pragmatic transfer occurred among all the 20 participants in the IEPG. The total number of wrong replies accounted for $40 \%$, in which Item 1 had the highest score $(\mathrm{T}=14, \mathrm{P}=70 \%)$ and the second highest were both, Item 4 and $5(\mathrm{~T}=9, \mathrm{P}=45 \%)$. This means that the majority of learners were inclined to rely on pragmatic transfer while they completed the DCT. This also suggests that the learners showed different levels of pragmatic competence ${ }^{[1]}$ under such situations. The lowest scores were Item 2 $(\mathrm{T}=3, \mathrm{P}=15 \%)$ and Item $3(\mathrm{~T}=5, \mathrm{P}=25 \%)$, where it seems that only a few learners were influenced by pragmatic transfer in these two contexts.

Table 1. Result of pragmatic transfer by each participant in IEPG

\begin{tabular}{|c|c|c|c|c|c|c|c|c|c|c|c|c|c|c|c|c|c|c|c|c|c|c|}
\hline Statement \ & 1 & 2 & 3 & 4 & 5 & 6 & 7 & 8 & 9 & 10 & 11 & 12 & 13 & 14 & 15 & 16 & 17 & 18 & 19 & 20 & Total & Percentage \\
\hline Participant & $\mathrm{F}$ & M & $\mathrm{F}$ & $\mathrm{F}$ & M & $\mathrm{F}$ & $\mathrm{F}$ & $\mathrm{F}$ & M & M & $\mathrm{F}$ & $\mathrm{M}$ & $\mathrm{F}$ & $\mathrm{F}$ & $\mathrm{F}$ & $\mathrm{F}$ & $\mathrm{F}$ & $\mathrm{F}$ & $\mathrm{F}$ & $\mathrm{M}$ & & \\
\hline 1 & & $\mathrm{X}$ & $\mathrm{X}$ & & $\mathrm{X}$ & $\mathrm{X}$ & $\mathrm{X}$ & $\mathrm{X}$ & $\mathrm{X}$ & & $\mathrm{X}$ & & & & $\mathrm{X}$ & $\mathrm{X}$ & $\mathrm{X}$ & $\mathrm{X}$ & $\mathrm{X}$ & $\mathrm{X}$ & $* 14$ & $70 \%$ \\
\hline 2 & & & & $\mathrm{X}$ & & & & & $\mathrm{X}$ & & & & & $\mathrm{X}$ & & & & & & & $\# 3$ & $15 \%$ \\
\hline 3 & & $\mathrm{X}$ & $\mathrm{X}$ & & & & & & & & & & & & & $\mathrm{X}$ & & & $\mathrm{X}$ & $\mathrm{X}$ & 5 & $25 \%$ \\
\hline 4 & $\mathrm{X}$ & & & & $\mathrm{X}$ & $\mathrm{X}$ & & $\mathrm{X}$ & & $\mathrm{X}$ & & & $\mathrm{X}$ & $\mathrm{X}$ & & & & $\mathrm{X}$ & & $\mathrm{X}$ & 9 & $45 \%$ \\
\hline 5 & & & $\mathrm{X}$ & & & $\mathrm{X}$ & $\mathrm{X}$ & $\mathrm{X}$ & & & & $\mathrm{X}$ & $\mathrm{X}$ & $\mathrm{X}$ & $\mathrm{X}$ & & & & & $\mathrm{X}$ & 9 & $45 \%$ \\
\hline $\begin{array}{c}\text { Total number of } \\
\text { wrong replies }\end{array}$ & 1 & 2 & 3 & 1 & 2 & 3 & 2 & 3 & 2 & 1 & 1 & 1 & 2 & 3 & 2 & 2 & 1 & 2 & 2 & 4 & 40 & $40 \%$ \\
\hline $\begin{array}{l}\text { Total number of } \\
\text { correct replies }\end{array}$ & 4 & 3 & 2 & 4 & 8 & 2 & 3 & 2 & 3 & 4 & 4 & 4 & 3 & 2 & 3 & 3 & 4 & 3 & 3 & 1 & 60 & $60 \%$ \\
\hline
\end{tabular}

In Table 2, only 5 participants in the advanced group (AEPG) scored 5 points, which means that $25 \%$ of the participants in this group were influenced by pragmatic transfer while completing the DCT. As shown in Table 2, the total number of wrong replies accounted for $26 \%$. Item $5(\mathrm{~T}=7, \mathrm{P}=35 \%)$ had the highest score, which indicates that more than one-third of the learners in AEPG were under the influence of pragmatic transfer whereas Item $3(\mathrm{~T}=4, \mathrm{P}=20 \%)$, which scored the lowest, implies that a small fraction of advanced learners was under the influence of pragmatic transfer in this context.

Table 2. Result of pragmatic transfer by each participant in AEPG

\begin{tabular}{|c|c|c|c|c|c|c|c|c|c|c|c|c|c|c|c|c|c|c|c|c|c|c|}
\hline Statement $\backslash$ & 1 & 2 & 3 & 4 & 5 & 6 & 7 & 8 & 9 & 10 & 11 & 12 & 13 & 14 & 15 & 16 & 17 & 18 & 19 & 20 & Total & Percentage \\
\hline Participant & $\mathrm{F}$ & $\mathrm{F}$ & $\mathrm{F}$ & $\mathrm{M}$ & $\mathrm{F}$ & $\mathrm{M}$ & $\mathrm{F}$ & $\mathrm{M}$ & $\mathrm{F}$ & $\mathrm{F}$ & $\mathrm{F}$ & $\mathrm{M}$ & $\mathrm{M}$ & M & $\mathrm{F}$ & $\mathrm{F}$ & $\mathrm{F}$ & $\mathrm{F}$ & $\mathrm{F}$ & $\mathrm{M}$ & & \\
\hline 1 & & & & $\mathrm{X}$ & & & $\mathrm{X}$ & & & & & & & & & $\mathrm{X}$ & & & $\mathrm{X}$ & $\mathrm{X}$ & 5 & $25 \%$ \\
\hline 2 & $\mathrm{X}$ & & $\mathrm{X}$ & & & & & & & & $\mathrm{X}$ & & & $\mathrm{X}$ & & $\mathrm{X}$ & & & & & 5 & $25 \%$ \\
\hline 3 & & & $\mathrm{X}$ & & & & & & & & $\mathrm{X}$ & & $\mathrm{X}$ & & $\mathrm{X}$ & & & & & & \#4 & $20 \%$ \\
\hline 4 & & & $\mathrm{X}$ & & & & $\mathrm{X}$ & $\mathrm{X}$ & & & & $\mathrm{X}$ & & $\mathrm{X}$ & & & & & & & 5 & $25 \%$ \\
\hline 5 & & & $\mathrm{X}$ & $\mathrm{X}$ & $\mathrm{X}$ & $\mathrm{X}$ & & & & & & & & $\mathrm{X}$ & & $\mathrm{X}$ & & & $\mathrm{X}$ & & $* 7$ & $35 \%$ \\
\hline $\begin{array}{c}\text { Total number of } \\
\text { wrong replies }\end{array}$ & 1 & 0 & 4 & 2 & 1 & 1 & 2 & 1 & 0 & 0 & 2 & 1 & 1 & 3 & 1 & 3 & 0 & 0 & 2 & 1 & 26 & $26 \%$ \\
\hline $\begin{array}{l}\text { Total number of } \\
\text { correct replies }\end{array}$ & 4 & 5 & 1 & 3 & 4 & 4 & 3 & 4 & 5 & 5 & 3 & 4 & 4 & 2 & 4 & 2 & 5 & 5 & 3 & 4 & 74 & $74 \%$ \\
\hline
\end{tabular}

The comparison of the percentages of wrong replies in the IEPG and AEPG are shown in Table 3. In the IEPG, the percentages of wrong replies for Statement 1 (S1) to Statement 5 (S5) were 70\%, 15\%, 25\%, $45 \%$, and $45 \%$, respectively. In the AEPG, the percentages from S1 to S5 were $25 \%, 25 \%, 20 \%, 25 \%$, and $35 \%$, respectively. The percentages for the total number of wrong replies of IEPG and AEPG were $40 \%$ 
and 26\%, respectively. Therefore, in this study, it appears that learners in IEPG depended much less on pragmatic transfer compared to the learners in AEPG; that is, more pragmatic transfer was found among learners with intermediate-level English proficiency compared to learners with high-level English proficiency.

Table 3. Percentages of wrong replies in IEPG and AEPG

\begin{tabular}{ccccccc}
\hline Participant $\backslash$ Statement & 1 & 2 & 3 & 4 & 5 & Total \\
\hline IEPG & $70 \%$ & $15 \%$ & $25 \%$ & $45 \%$ & $45 \%$ & $\mathbf{4 0 \%}$ \\
AEPG & $25 \%$ & $25 \%$ & $20 \%$ & $25 \%$ & $35 \%$ & $\mathbf{2 6 \%}$ \\
\hline
\end{tabular}

\subsection{Implications}

Since pragmatic transfer can generate barriers in achieving effective and successful cross-cultural communication, it is significantly necessary to develop the pragmatic competence of Chinese EFL learners. The sufficient and effective input of pragmatic knowledge of the target language should be brought into consideration to assist Chinese learners in eliminating the interference from their mother tongue. Hence, some suggestions and strategies are provided below.

(1) Cultivating learners' cross-cultural awareness.

In order to ensure appropriate cross-cultural communications, Chinese EFL learners should seek for similarities and differences between the Chinese culture and the cultures in English-speaking countries by comparing and contrasting. These comparisons and contrasts are meant to enrich learners' experiences and for them to be aware of the diversity and distinction between these two varieties of cultures.

(2) Challenging traditional pedagogy.

In China, opportunities for EFL learners to expose themselves to the target language community or environment are limited. The learners' English proficiency and communicative competence are achieved principally through formal teachings, which are usually oriented to passing various examinations. However, language teaching and learning should be aimed for actual communication, thus the pragmatic awareness and competence of Chinese EFL learners should be developed. In order to achieve this goal, learners should gain access to abundant authentic materials and more interpersonal contacts with English native speakers.

(3) Producing adequate input of pragmatic knowledge.

The goal of Chinese EFL learners is not only to master what to say in the target language, but also how to say it appropriately. It is also quite essential to learn some communication principles. Therefore, where speech acts are concerned, introducing locutionary act, illocutionary act, and perlocutionary act to learners are good ways to improve learners' pragmatic awareness.

\section{Conclusion}

The study, presented in this paper, focused on the phenomenon of pragmatic transfer in the speech act of compliment. The results indicate that Chinese EFL learners indeed do carry out pragmatic performance from Chinese to English, and the pragmatic transfer is consistent with their English language proficiency.

In order to change the present embarrassing situation, several suggestions and proposals for teaching should be taken into account. Chinese EFL teachers should cultivate learners' cross-cultural awareness, make several changes to the traditional teaching methods, and generate sufficient input of pragmatic 
knowledge. After all, the goal of teaching and learning the English language in the context of Chinese EFL is to develop genuine communication, hence pragmatic competence should by no means be neglected.

\section{Disclosure statement}

The author declares that there is no conflict of interest.

\section{References}

[1] Tian YL, 2002, Pragmatic Transfer in Greetings and its Relationship to English Proficiency among Chinese EFL Learners. Unpublished MA Thesis, La Trobe University, : 1-2, 4, 38.

[2] Lado R, 1957, Linguistics Across Culture: Applied Linguistics for Language Teachers. University of Michigan Press, Ann Arbor, : 24.

[3] Yamagashira H, 2001, Pragmatic Transfer in Japanese ESL Refusals. Journal of Kagoshima Immaculate Heart College, English Department, 31: 259-75.

[4] Beebe LM, Takahashi T, Uliss-Weltz R, 1990, Pragmatic Transfer in EFL Refusals, in On the Development of Communicative Competence in a Second Language, Scarcella RC, Anderson E, Krashen SD, Newbury House, New York, 55-73.

[5] Kasper G, 1992, Pragmatic Transfer. Second Language Research, 8(3): 203-31.

[6] Holmes J, 1986, Compliments and Compliment Responses in New Zealand English. Anthropological Linguistics, 28: 485-508.

[7] Ye L, 1995, Complimenting in Mandarin Chinese, in Pragmatics of Chinese as Native and Target Language, Kasper G, University of Hawaii, Manon, 207-302.

[8] Holmes J, Brown DF, 1987, Teachers and Students Learning About Compliments. TESOL Quarterly, 21(3): 523-46.

[9] Blum-Kulka S, House J, 1989, Cross-Cultural and Situational Variation in Requesting Behavior, in Cross-Cultural Pragmatics, Blum-Kulka S, Mouron, Berlin, 123-55.

[10] Chen R, 1993, Responding to Compliments: A Contrastive Study of Politeness Strategies between American English and Chinese Speakers. Journal of Pragmatics, 20(1): 49-75.

[11] Chen Ye, Zhang, 1995, Refusing in Chinese, in Pragmatics of Chinese as Native and Target Language, Kasper G, University of Hawaii, Manon, 119-63.

[12] Oldin T, 1989, Language Transfer: Cross-Linguistic Influence in Language Learning. Cambridge. Cambridge University Press.

[13] Takahashi T, Beebe LM, 1987, The Development of Pragmatic Competence by Japanese Learners of English. JALT Journal, 8: 131-51.

[14] Yule G, 1996, Pragmatics. Oxford University Press, Oxford.

[15] Zegarac V, Pennington MC, 2000, Pragmatic Transfer in Intercultural Communication, in Culturally Speaking: Managing Rapport Through Talk Across Culture, Spencer-Oatey H, Continuum, London and New York, 165-90. 